\title{
Characterisation of Chromium-Copper- Arsenic (CCA) treated wood waste from a steel-making environment
}

\author{
S. Raghuyal, J. Steer, A. Griffiths \& A. Hopkins \\ School of Engineering, Cardiff University, UK
}

\begin{abstract}
Copper Chromium Arsenic (CCA) treated wood is used in the construction of coke oven quenching towers in integrated steel-plants and many other industrial applications. Waste arising from such wood has been deemed as hazardous by the recent environmental regulations due to the high heavy metal content. Hence disposal of CCA wood is substantially more expensive.

The aim of this paper was to characterise the waste arising from a typical 33 years old coke quenching tower and to give an evaluation for the disposal methods in accordance to current environmental regulations. During the tower demolition, different wood samples were taken from old and renovated sections as well as support beams.

Elemental analysis of the wood indicated that CCA concentration ranged from $300 \mathrm{mg} / \mathrm{kg}$ to $11,000 \mathrm{mg} / \mathrm{kg}$ decreasing with the age of treated wood. In addition, a high iron concentration was found from $250 \mathrm{mg} / \mathrm{kg}$ to $18000 \mathrm{mg} / \mathrm{kg}$, increasing with the age of treated wood. An analysis of the CCA distribution among the growth-rings of cross-sectioned support beam along the sides as well as to the core of the beam was performed. Water leaching on the CCA wood was also performed up to 1 month duration. CCA elements leached more with increase in leaching duration where arsenic was quickest to leach at $100 \mathrm{mg} / \mathrm{kg}$ compared chromium being slowest at $21 \mathrm{mg} / \mathrm{kg}$ for 1 hour duration. Continuous leaching and interrupted leaching tests were also performed to further characterise the leaching behaviour of the CCA wood. To complete the characterisation, SEM analysis was conducted and the results were compared against untreated wood.
\end{abstract}


This characterisation provided a valuable insight into the investigation of potential processes for recovery, reuse or disposal of the CCA treated wood in accordance to environmental norms.

Keywords: characterisation, quenching tower, chromate copper arsenate, CCA, treated wood, wood waste, hazardous waste, leaching, SEM.

\section{Introduction}

Wood is a major construction material in various industrial applications and is especially used in a coke quenching tower. But as wood is an organic material it is susceptible to decay and decomposition. To prevent deterioration wood is treated with a waterborne preservative called Copper Chromium Arsenic (CCA). This preservative is administered in an industrially sealed treatment cylinder under vacuum and pressure cycles [1]. The preservative consists essentially of a mixture of a copper (II), chromium (VI) and arsenic (V). Copper is the primary fungicide and highly effective molluscicide. Arsenic is the secondary fungicide and very effective insecticide and chromium gives protection from ultra-violet light and is responsible of fixating copper and arsenic into the wood lattice [2].

Copper, chromium and arsenic carry potential risks to human health and environment. Though chromium (III) has low toxicity, chromium (VI) is highly toxic due to strong oxidation characteristics and permeability through biological membranes. Excessive exposure to Chromium can cause lung cancer and cancer of respiratory tract as well as it has teratogenic effects in animals by causing birth defects and fertility issues. Symptoms of acute arsenic poisoning include burning lips, constriction of throat, abdominal pain, severe nausea and profuse diarrhoea. Copper compounds are known to be poisonous to aquatic life [3]. Exposure to these elements can be due to direct contact with the treated wood (touching the treated wood.), exposure to the material contaminated with preservatives from the treated wood (contaminated soil or food grown in contaminated soil), Exposure through inhalation (dermal sorption or inhalation of wood particles) [4] and exposure of organisms to treated wood in environment (absorption of preservatives by plants or animals).

With effect from $6^{\text {th }}$ January 2003, European Directive 2003/2/EC clause 6 classified CCA treated wood waste as hazardous [5]. The United Kingdom environment regulations stated stricter regulations on the use and marketing of the CCA treated wood. This treated wood is restricted for professional and industrial purpose only where skin contact by the general public is unlikely during its service life. The waste generated for this kind of wood should be deemed as hazardous and should be disposed according to the hazardous waste disposal regulations as mentioned in Environment Protection Regulations [6]. Although now restricted, quantity of CCA treated wood waste will continue to increase in waste stream for next 50 years with very few recycle or reuse options [7]. There is about $60,000 \mathrm{~m}^{3}$ of CCA treated wood waste which is predicted to rise to about $850,000 \mathrm{~m}^{3}$ in UK waste stream as presented by Murphy and Hillier [8].

Even though the waste is classified as hazardous it is necessary to fully characterise the waste and its constituents. The objective of this paper was to 
perform a full characterisation of the treated wood waste arising from a typical coke quenching tower from an integrated steelworks site. To recognise the strategic sampling points on the quenching tower and analyse the wood for CCA presence. Growth ring analysis for the CCA distribution was also performed. Different tests were performed to obtain a better understanding of the leaching behaviour. Leaching tests up to 1 month as well as tailored leaching tests were performed. For further characterisation purposes scanned electron microscopy (SEM) was also performed.

\section{Wood samples}

\subsection{Sample collection}

All the samples were obtained from a coke quenching tower at integrated steel works in South Wales, United Kingdom. The quenching tower was erected in 1977 and had been in service till 2010. Tower was mainly a wooden structure which included wooden planks, staircases and support beams of redwood (Pinus sylvestris) and the schematic is shown in figure 1. All the wooden parts of the tower were treated with CCA in accordance to British Standard BS4072 [1]. The tower had undergone renovation twice since commissioning and was fitted with fresh treated wood. Once in early 2001 and second when a replacement tower was constructed in 2008 on the other end of coke ovens plant. The tower had three sections: Lower triangle section with a water runoff area at the bottom of quenching tower with $5.2 \mathrm{~m}$ height, Middle section, a water spray zone above triangle section with $6 \mathrm{~m}$ height and Top section was the vent for steam above middle section with $6.4 \mathrm{~m}$ height. A number of sampling points were recognised before tower demolition.

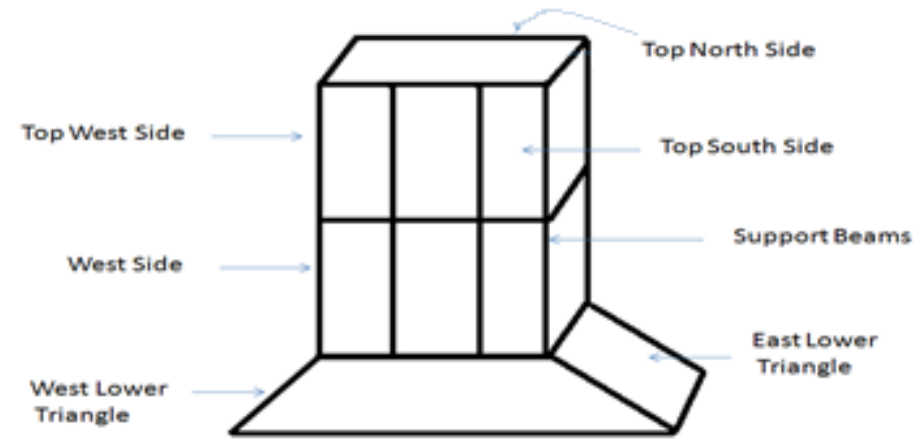

Figure 1: Schematic of coke quenching tower and sampling points.

From every section of the tower, samples were collected, depending on the age of wood; wood from year 1977 was classed as being old and the rest was deemed to be new. Sample of the support beams were also taken. Samples of untreated wood were obtained from a local wood treatment plant. 


\subsection{Sample preparation}

All the samples were plank shaped other than the support beam sections. The planks were cut to $300 \mathrm{~mm}$ length using an electric band saw and then slithers were cut out of the planks. This made it easier to ground the sample into sawdust using a knife mill. Similarly, untreated wood sample was prepared in the same way. Slices of $3 \mathrm{~mm}$ to $4 \mathrm{~mm}$ thick were cut from the support beams and then ground. Therefore, all ground samples and sawdust obtained were considered as homogenous sample for analysis purposes. All samples obtained were dried according to the British Standard BSEN 14346 [9] and bagged in plastic lip seal pockets for air tight moisture free storage. Such that all the tests were performed on dried sample from the coke quenching tower.

\section{Elemental analyses}

An Inductively Coupled Plasma- Optical Emission Spectrometry (ICP-OES) was used to measure the amount of metal present in the samples. The digestion of wood was based on wet ashing procedure as per American Wood Protection Association Standard (AWPA) A7-04 [10]. 8ml of nitric acid and $3 \mathrm{ml}$ of hydrogen peroxide were added to a $0.5 \mathrm{gm}$ of dried wood sample in a microwave digestion tube. The digestion tubes were placed into the digestion vessels with caps screwed to a firm fit. Digestion vessels were placed into the carousel in microwave oven and a pre-programmed digestion sequence was started. After digestion was completed the vessels contents were removed and volumes were made to a $100 \mathrm{ml}$ with de-ionised water. The digested samples were measured for the metal content using the PerkinElmer Optima 2100DV, ICP instrument.

\subsection{Results and discussion}

All the wood samples were tested for the main three elements as copper, chromium and arsenic as well as the three secondary elements as iron, zinc and lead. A baseline of the elemental composition was established by testing a known natural untreated wood for the six elements. The results for the untreated wood in figure 2 showed that there was no copper and lead present and

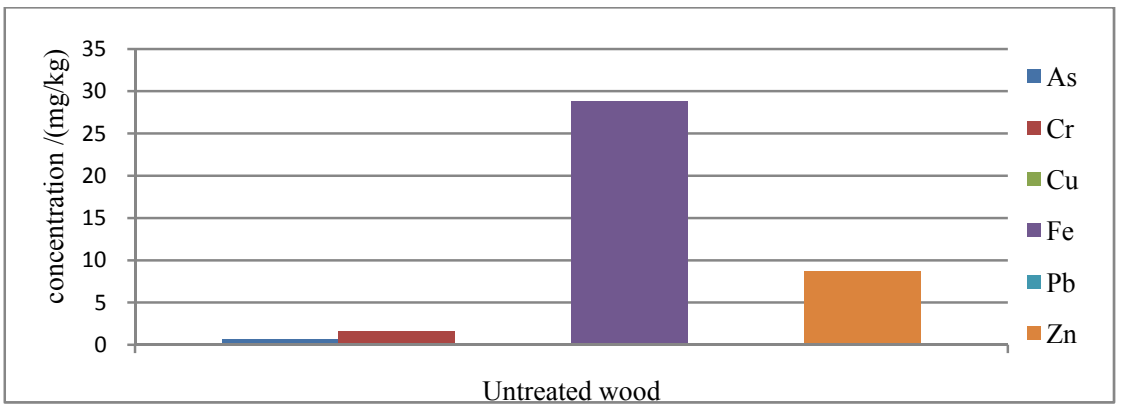

Figure 2: $\quad$ Elemental analysis of natural untreated wood. 
chromium and arsenic in traces whereas iron and zinc are $30 \mathrm{mg} / \mathrm{kg}$ and $10 \mathrm{mg} / \mathrm{kg}$ respectively as elements present in wood naturally.

Results of the elemental analysis of the wood shown in figure 3 confirmed that they were originally treated with CCA preservative and still contain considerable amount of heavy metals. The concentration of copper, chromium and arsenic varied widely due to difference in age and location of sample on the quenching tower. Over the period, a substantial amount of copper, chromium and arsenic had leached out. The lower triangle area which received a heavy water wash out during every quench cycle had the least amount of CCA, the west side of lower triangle contained $236 \mathrm{mg} / \mathrm{kg}, 1759 \mathrm{mg} / \mathrm{kg}$ and $409 \mathrm{mg} / \mathrm{kg}$ of arsenic, chromium and copper respectively. The East side of lower triangle area contained $138 \mathrm{mg} / \mathrm{kg}, 609 \mathrm{mg} / \mathrm{kg}$ and $91 \mathrm{mg} / \mathrm{kg}$ of arsenic, chromium and copper respectively. The new wood which was installed in last ten years retained most of the heavy metal content. The old wood samples have shown a significant leaching of the metals especially arsenic and copper levels in wood were much lower than chromium. Hence an anticipated trend of the loss of CCA elements was detected i.e. CCA concentration reduced with the increase in the age of the wood.

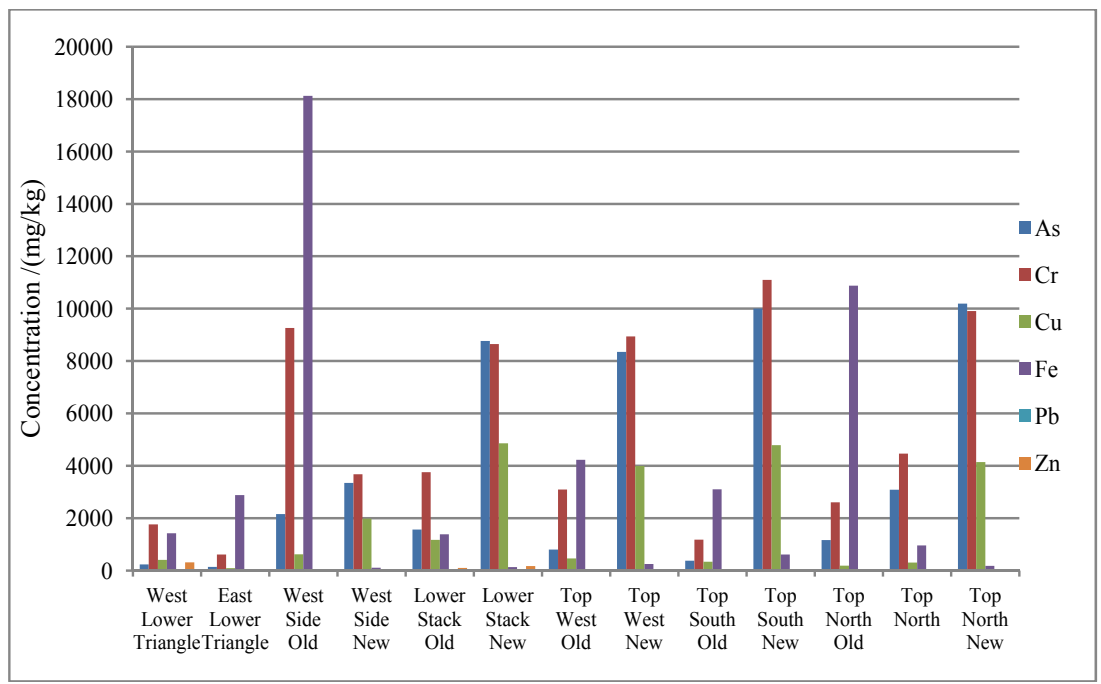

Figure 3: Elemental analyses of different quenching tower wood samples.

But on the other hand unusual concentrations of iron were recorded which ranged from $111 \mathrm{mg} / \mathrm{kg}$ in the new wood samples to $18127 \mathrm{mg} / \mathrm{kg}$ in the old wood samples. Thus iron concentration increased with the increase in age of the wood. It was important to study the source of iron as this would help in determination of how iron is attached to the wood lattice. Also to ensure that iron was limited to a waste wood from quenching tower or it could be found in treated wood waste streams from other industrial applications. 


\subsection{Iron source determination}

Elemental analysis of wood samples revealed that a very high concentration of iron in wood such that concentration was directly proportional to the age of wood. This meant that iron was introduced slowly in the wood over the service period of quenching tower. Although quenching tower does not directly play any role in steel making, but being a part of an integrated steel-plant there are various ways of iron entering in the wood.

\subsubsection{Coke ash analysis}

One of the means of wood receiving iron could be from the process of quenching itself where any iron in coke ash may get absorbed in the wood. Analysis of the coke ash over a period of 10 months was obtained. During this period the elemental composition of coke ash had been consistent with iron oxide at about $8 \%$ of the total composition with $50 \%$ silicon oxide and $30 \%$ aluminium oxide as shown in figure 4.

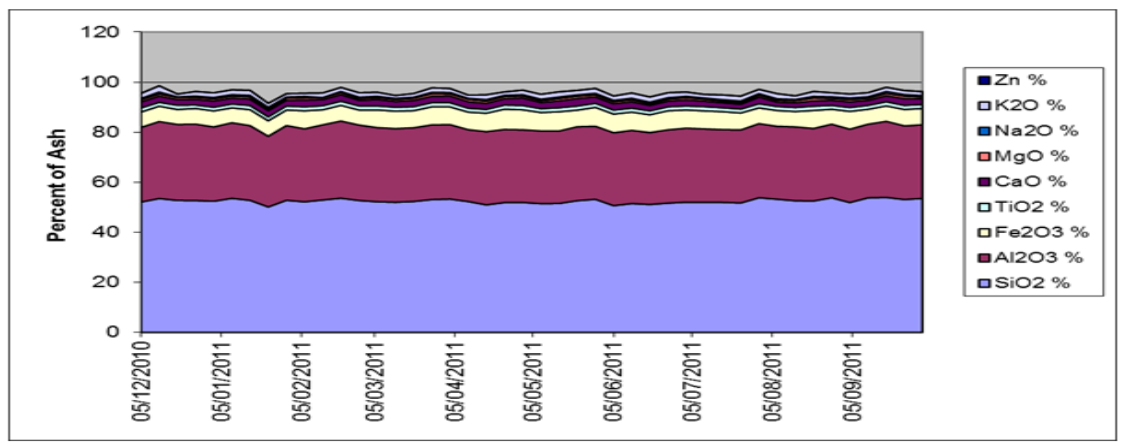

Figure 4: Coke ash analysis.

Therefore the wood samples were evaluated for aluminium and silicon concentration as well. Aluminium and silicon concentration were found to be relatively higher in the older wood as compared to the new wood. Hence, the trend of increase in concentration with increase in the age also holds true for aluminium and silicon but at much lower levels.

\subsubsection{Quench water analysis}

Analysis of water before and after the quench cycle was performed to check if water played any role in the increase iron concentration. Concentration of the elements in the water before and after the quench cycle can be seen in Table 1. There is considerable amount of silicon in the water before cycle and an elevated amount of silicon leaves out with the water after the cycle. Whereas iron concentration remains constant and negligible amount of aluminium were recorded after quench cycle. Iron has more affinity for the wood than aluminium and less susceptible to leaching than silicon. 
Table 1: $\quad$ Aluminium, silicon and iron in wood and quenching water.

\begin{tabular}{|l|r|r|r|}
\hline \multirow{2}{*}{ Location } & \multicolumn{2}{|c|}{ Element concentration (mg/kg) } \\
\cline { 2 - 4 } & Aluminium & \multicolumn{1}{c|}{ Iron } & \multicolumn{1}{c|}{ Silicon } \\
\hline West Side Old & 431 & 15134 & 1035 \\
\hline West Side New & 75 & 116 & 1092 \\
\hline Top West Old & 274 & 3932 & 90 \\
\hline Top West New & 87 & 216 & 959 \\
\hline Lower Stack Old & 662 & 1336 & 53 \\
\hline Lower Stack New & 115 & 117 & 4.61 \\
\hline Water Before Quench Cycle & 0 & 0.03 & 7.78 \\
\hline Water After Quench Cycle & 0.02 & 0.03 & \multicolumn{1}{|c|}{ (15) } \\
\hline
\end{tabular}

Concentration of iron could also be increased due to the location of the quenching tower in an integrated steel works where a high amount of iron is airborne in the form of kish. Kish can be defined as the waste material that forms the top layer of the molten metal (hot metal) during the process of steel making. Iron forms about $50 \%$ of the kish composition [11]. Kish is attracted towards a wet wood and ultimately gets adsorbed and attached to the wood surface. Iron content on the wood surface was $1569 \mathrm{mg} / \mathrm{kg}$ compared to the core of wooden planks at $48 \mathrm{mg} / \mathrm{kg}$. Hence the iron builds a layer on the wood surface over time either being adsorbed directly from air or from the coke ash.

\subsection{Growth ring analysis}

Two types of assessments were performed to study the growth rings: edge and diagonal assessment. Samples were prepared by cutting the support beam in cross-sectioned to $5 \mathrm{~mm}$ thickness.

1. Edge assessment

The growth rings on either side of the cross-sectioned sample were carved out to a length of $30 \mathrm{~mm}$ and were analysed using the ICP technique.

2. Diagonal assessment

A whole growth ring was cut out of the cross-sectioned sample and was further cut into four pieces of $40 \mathrm{~mm}$ length.

From the edge assessment, it was observed that growth rings contained a fairly constant amount of copper at $25 \mathrm{mg} / \mathrm{kg}$ whereas chromium and arsenic were inconsistent with high readings at random growth rings. A substantial amount of iron was also recorded with consistent readings at about $485 \mathrm{mg} / \mathrm{kg}$.

The diagonal assessment revealed that negligibly small CCA is present in the centre of wood. It also showed high iron reading of $276 \mathrm{mg} / \mathrm{kg}$ for growth ring pieces from the edge of the beam compared to centre parts where iron content was $10 \mathrm{mg} / \mathrm{kg}$. Hence, this displayed that most of the iron present was on the surface of all wooden structures. 


\section{Leaching}

\subsection{Standard leaching}

All leaching test were performed in accordance to British Standard BS12457-2 [12] with a solid to liquid ratio of 1:10. All the samples were ground to a size less than $4 \mathrm{~mm}$ and dried at $105^{\circ} \mathrm{C}$ as per British Standard BS EN 14346 [1]. Leaching involved $5 \mathrm{~g}$ of sawdust sample in $50 \mathrm{ml}$ of de-ionised water stirred by a magnetic stirrer $(150-250 \mathrm{rpm})$ at room temperature $(20+5)^{\circ} \mathrm{C}$. These tests were completed in triplicates for 1 hour, 1day, 1week and 1month of time duration.

All the tests were conducted on 'west side new' wood sample, with $3496 \mathrm{mg} / \mathrm{kg}, 3845 \mathrm{mg} / \mathrm{kg}$ and $1996 \mathrm{mg} / \mathrm{kg}$ of arsenic, copper and chromium preleach concentrations respectively. Leaching results showed that arsenic was the quickest to leach followed by copper and slowest was chromium out of CCA elements. Leaching concentration increased with prolonged exposure of wood to water with maximum concentration of arsenic, chromium and copper was $306 \mathrm{mg} / \mathrm{kg}, 65 \mathrm{mg} / \mathrm{kg}$ and $122 \mathrm{mg} / \mathrm{kg}$ respectively for 1 week leaching period, at this point water was saturated with the maximum soluble CCA elements. Figure 5 highlights the results obtained during the standard leaching tests.

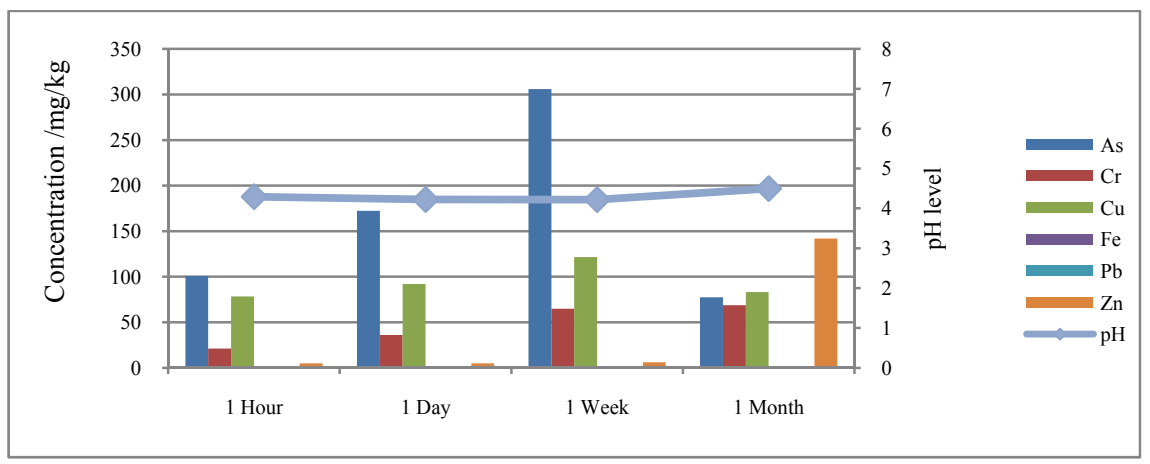

Figure 5: Leaching from quenching tower wood for different time duration with respective $\mathrm{pH}$ levels.

In order to maintain the equilibrium, elements from saturated water was reabsorbed in the wood when leaching duration exceeded more than 1 week. Hence, the leachability of elements dropped for 1 month period. Concentration of arsenic, chromium and copper were $77 \mathrm{mg} / \mathrm{kg}, 69 \mathrm{mg} / \mathrm{kg}$ and $83 \mathrm{mg} / \mathrm{kg}$ respectively for 1 month leaching period. Iron proved to be resistant to leaching for any duration, whereas zinc leached at a very slow rate. The leaching rates confirmed that the CCA wood waste was still capable of loosing substantial amount of heavy metals and should be disposed as hazardous.

All leaching tests took place at around $\mathrm{pH} 4-4.5$ for standard conditions with no major changes in $\mathrm{pH}$ levels. 


\subsection{Continuous leaching}

A continuous leaching trial was a custom designed leaching test. The procedure was the same as of British Standard BS 12457-2 [12] with time duration of 3 hour and solid to liquid ratio as 1:10. During the 3 hour period, after every 1 hour of leaching process a $2 \mathrm{ml}$ sample of leachant was taken from the ongoing leaching test (without disturbing the apparatus). Therefore at the end of three hour period three samples were available for elemental analysis. This test provided a continuous update of ongoing leaching behaviour of the elements in wood water system. This test was carried out on the same type of wood samples used in standard leaching tests.

The results of the continuous leaching showed an exponential increase in the leaching of CCA element with arsenic as the quickest to leach at $118 \mathrm{mg} / \mathrm{kg}$ followed by copper at $91 \mathrm{mg} / \mathrm{kg}$ and then chromium at $24 \mathrm{mg} / \mathrm{kg}$. After two hours the leaching process was near its saturation point as by third hour change in arsenic concentration increased very slowly from $165 \mathrm{mg} / \mathrm{kg}$ to $169 \mathrm{mg} / \mathrm{kg}$ with copper concentration started to dropped from $114 \mathrm{mg} / \mathrm{kg}$ to $104 \mathrm{mg} / \mathrm{kg}$ and chromium maintain its concentration around $33-34 \mathrm{mg} / \mathrm{kg}$. Results of continuous leaching were in agreement with a standard one day leaching process where arsenic, copper and chromium were $172 \mathrm{mg} / \mathrm{kg}, 92 \mathrm{mg} / \mathrm{kg}$ and $36 \mathrm{mg} / \mathrm{kg}$. The results are highlighted in figure 6.

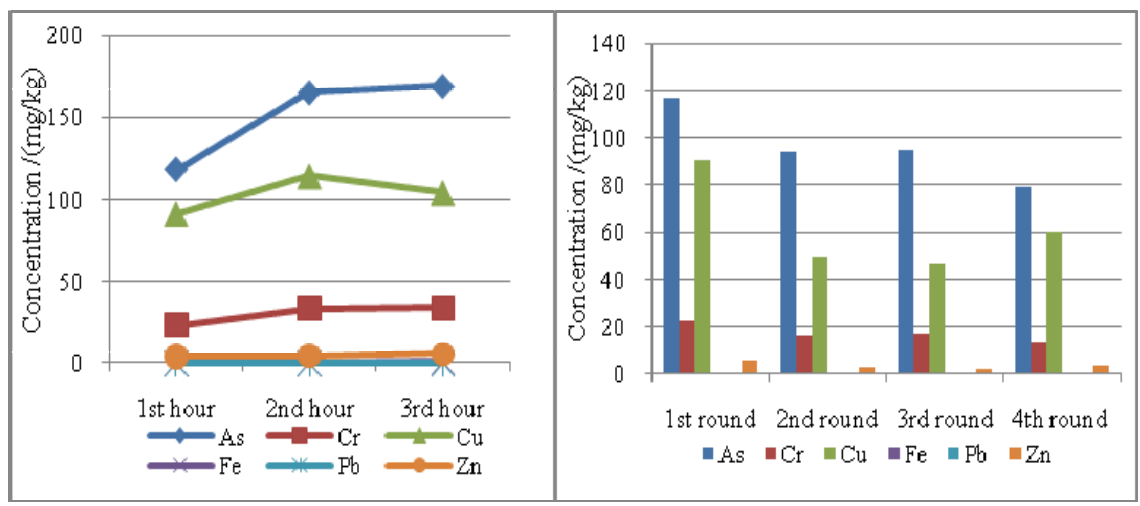

Figure 6: (Left) Continuous leaching, (Right) interrupted leaching.

\subsection{Interrupted leaching}

Interrupted leaching was another custom designed leaching process with same procedure as of British Standard BS 12457-2 [12]. Leaching time was 1 hour and solid to liquid ratio as 1:10. After an hour of leaching, the solid and solute were separate. Where solids were collected and oven dried at $105^{\circ} \mathrm{C}$ and elemental analysis to be carried out on solute. On the remaining dried sample, leaching cycle was repeated 3 more times. At the end of the $4^{\text {th }}$ cycle four solute samples were received and analysed. 
The same leaching pattern was noticed, arsenic was the quickest to leach with highest concentration followed by copper and chromium being the most resistant to leach of CCA elements. With average concentration of $96 \mathrm{mg} / \mathrm{kg}, 18 \mathrm{mg} / \mathrm{kg}$ and $61 \mathrm{mg} / \mathrm{kg}$ for arsenic, chromium and copper respectively leached per cycle. Leaching relationship between the three CCA elements was found such that copper leaches 3.5 times more than chromium and arsenic leaches 5.5 times more than chromium for all 1 hour leach cycles. This relationship was also observed for standard leaching results and held true until the saturation point was reached.

Hence, in total for interrupted leaching a lot more of CCA elements leached when compared to similar duration of leaching for wood in three continuous hours leach cycle.

\section{Scanning electron microscope (SEM)}

A wooden plank was cut in two along its length. Along the side of one of the pieces of the wooden plank a sample was stripped of $1 \mathrm{~mm}$ thickness using a band saw. The strip was cut into $10 \mathrm{~mm}$ squares and was oven dried at $105^{\circ} \mathrm{C}$ until moisture free. Analysis of the sample under high vacuum using SE1 (Secondary Electron) detector was not possible due to sample charging.

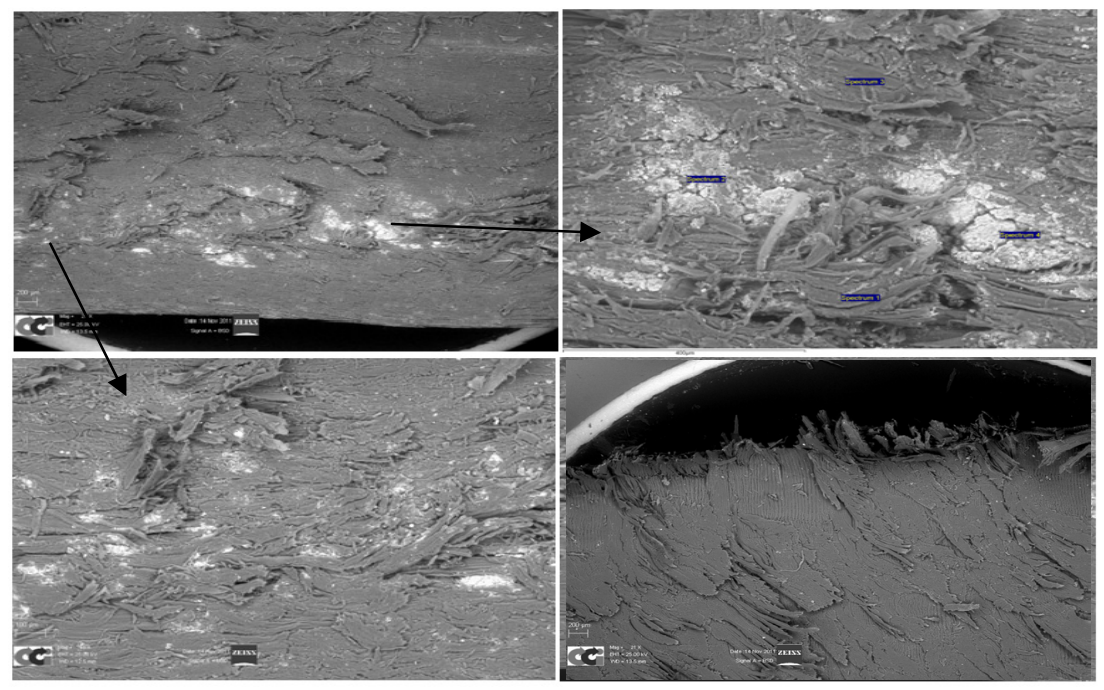

Figure 7: $\quad$ SEM images taken of a CCA treated and untreated wood sample. Top-right sample magnification at $200 \mu \mathrm{m}$, Top-left zoomed area with EDX testing points, bottom-left magnified image to $100 \mu \mathrm{m}$ and bottom-right image of untreated wood sample.

For this reason the sample was imaged using a backscatter detector and variable pressure set-up. Analysis was performed using Carl Zeiss EVO-40 
scanning electron microscope. EDX was done using Oxford Instruments detector and Inca analysis suite. All samples were analysed uncoated at $90^{\circ}$ tilt. The images obtained are highlighted in figure 7.

The SEM images were analysed for EDX, the presence of copper, chromium and arsenic in the treated wood was determined on the other hand no CCA was found in untreated wood sample. SEM images consisted of white spots which were analysed as calcium deposits. This calcium could be picked up by the treated wood during its service life but some calcium could also be present as natural nutrient of wood. A line scan of elemental analysis was performed on treated wood from the edge $(0 \mathrm{~mm})$ of the sample to the centre $(3 \mathrm{~mm})$. It was observed that concentration of chromium and arsenic decreased gradually as scan moved towards the centre. This depicted major CCA presence on the edges of the wood with reduced concentration in the core of the wood. Copper was not detected in the line scan due to the interference by copper tapes used in fixing the same to the machine.

\section{Conclusion}

The elemental analysis showed that the CCA content reduced with the increase in the age of wood. However the CCA content in all samples was substantial enough for the waste to be considered as hazardous and should be disposed according to the current environmental legislation. The elemental analysis also showed iron concentration in the wood and it increased with the increasing age of the wood. Iron source was suspected to be a gradual exposure of wood to the coke ash which contained about $8 \%$ Iron oxide. Also the location of quenching tower in an integrated steelworks led to a slow adsorption of airborne iron particles from kish. $1569 \mathrm{mg} / \mathrm{kg}$ of iron was recorded on the surface of the wood planks with only $48 \mathrm{mg} / \mathrm{kg}$ present in the core.

Growth ring analysis also showed iron concentration on the edges of the wood with traces of iron present in the core suggesting that iron accumulation was on the surface mainly. Just from the growth ring analysis a set pattern of CCA distribution could not be generated.

Standard leaching test revealed that arsenic was quickest to leach with a high concentration ranging from $100 \mathrm{mg} / \mathrm{kg}$ for 1 hour duration to $305 \mathrm{mg} / \mathrm{kg}$ for 1 week. 1 month test showed that leaching of metals had passed the saturation point and most of the CCA elements had reabsorbed in the wood for a 1:10 solidliquid ratio leach test. After conducting customised leaching tests it was observed that most of the elements leach in the 2-3 hours after which a saturation point was attained. Leaching relationship between the three CCA elements was found such that copper leaches 3.5 more than times chromium and arsenic leaches 5.5 more than times chromium for all 1 hour leach cycles. This relationship held true until the saturation point was reached even for standard leaching test.

SEM was performed on treated and untreated wood. EDX analysis showed decreasing chromium and arsenic concentration from the edge to the centre of wood in a line scan. Copper could not be detected in line scan due to the 
interference from copper tapings used in fixing the samples. Thus, CCA presence was higher on the edges than the core of wood.

Hence, wood from a coke quenching tower from an integrated steelworks was treated with CCA and needs to be disposed of according to the environmental regulations. The data gathered in this research paper provided substantial information on the elemental content of wood and its distribution. It also provided additional information regarding the foreign elements present and its sources. The leaching characteristics would help in determining the extraction and disposal of such treated hazardous wood waste.

\section{References}

[1] Copper/chromium/arsenic preparations for wood preservation, British Standard, BS 4072, 1999.

[2] Townsend, T.G. and Solo-Gabriele, H., Chromated copper arsenated as a wood preservative (Chapter 1), Environmental Impacts of Treated Wood, Taylor \& Francis, pp10-13, 2006.

[3] CCA type C Pressure-Treated wood, Material Safety Data Sheet (MSDS), American Pole \& Timber, MSDS\#CSI-048 www.americanpoleandtimber.com/pdf/cca-treated-wood-msds.pdf

[4] Beyond Pesticides, Pesticides and You, A Beyond Pesticides Fact Sheet, Chapter-Chromated Copper Arsenate (CCA) Treated Wood, volume 23, number 1, pp18-21, 2003.

[5] COMMISSION DIRECTIVE 2003/2/EC, Relating to restrictions on the marketing and use of arsenic, (tenth adaptation to technical progress to Council Directive 76/769/EEC), Official Journal of the European Communities, $6^{\text {th }}$ January 2003.

[6] Control on Dangerous Substances, Statutory Instruments (SI 2003/3274), The Environmental Protection Regulations, $13^{\text {th }}$ December 2003.

[7] Wood Waste for Biomass Fuel, TRADA Construction Briefings, Version 3, December 2011.

[8] Murphy, R. and Hillier, B., Estimating service life for wood products and its use in evaluating resources and supplies of recovered wood, Department of Biological Sciences, Imperial college of London. www.bfafh.de/inst4/45/ppt/4serlife.pdf

[9] Characterisation of waste - Calculation of dry matter by determination of dry residue or water content, British Standard, BS 14346, 2006.

[10] Standard for wet ashing procedures for preparing wood for chemical analysis, American Wood Protection Association Standard, AWPA A7-04, 2004.

[11] L.J., Nicks, F.H., Nehl and M.F. Chambers, Recovering flake graphite from steelmaking kish, JOM Journal Of The Minerals, Metals And Material Society, volume 47, Number 6, pp 48-51, June 1995.

[12] Characterisation of waste - Leaching - Compliance test for leaching of granular waste materials and sludges, British Standard, BS 12457-2, 2002. 